\title{
Mutually beneficial pollinator diversity and crop yield outcomes in small and large farms
}

\author{
Lucas A. Garibaldi, ${ }^{*}$ Luísa G. Carvalheiro, ${ }^{2}$ Bernard E. Vaissière, ${ }^{3}$ \\ Barbara Gemmill-Herren, ${ }^{4}$ Juliana Hipólito, ${ }^{5}$ Breno M. Freitas, ${ }^{6}$ Hien T. Ngo, ${ }^{7}$ \\ Nadine Azzu, ${ }^{4}$ Agustín Sáez, ${ }^{8}$ Jens Åström, ${ }^{9}$ Jiandong An, ${ }^{10}$ Betina Blochtein,,${ }^{11}$ \\ Damayanti Buchori, ${ }^{12}$ Fermín J. Chamorro García, ${ }^{13}$ Fabiana Oliveira da Silva, ${ }^{14}$ \\ Kedar Devkota, ${ }^{15}$ Márcia de Fátima Ribeiro, ${ }^{16}$ Leandro Freitas, ${ }^{17}$ Maria C. Gaglianone, ${ }^{18}$ \\ Maria Goss, ${ }^{19}$ Mohammad Irshad, ${ }^{20}$ Muo Kasina, ${ }^{21}$ Alípio J.S. Pacheco Filho, ${ }^{6}$ \\ Lucia H. Piedade Kiill, ${ }^{16}$ Peter Kwapong, ${ }^{22}$ Guiomar Nates Parra, ${ }^{13}$ Carmen Pires, ${ }^{23}$ \\ Viviane Pires, ${ }^{24}$ Ranbeer S. Rawal, ${ }^{25}$ Akhmad Rizali, ${ }^{26}$ Antonio M. Saraiva, ${ }^{27}$ \\ Ruan Veldtman, ${ }^{28,29}$ Blandina F. Viana, ${ }^{5}$ Sidia Witter, ${ }^{30}$ Hong Zhang $^{10}$
}

Ecological intensification, or the improvement of crop yield through enhancement of biodiversity, may be a sustainable pathway toward greater food supplies. Such sustainable increases may be especially important for the 2 billion people reliant on small farms, many of which are undernourished, yet we know little about the efficacy of this approach. Using a coordinated protocol across regions and crops, we quantify to what degree enhancing pollinator density and richness can improve yields on 344 fields from 33 pollinator-dependent crop systems in small and large farms from Africa, Asia, and Latin America. For fields less than 2 hectares, we found that yield gaps could be closed by a median of $24 \%$ through higher flower-visitor density. For larger fields, such benefits only occurred at high flower-visitor richness. Worldwide, our study demonstrates that ecological intensification can create synchronous biodiversity and yield outcomes.

M ore than 2 billion people are reliant on smallholder agriculture (farms with less than 2 ha) in developing nations, representing $83 \%$ of the global agricultural population $(1,2)$. In such countries, human population is growing faster than in developed nations, while many of the rural inhabitants are poor, undernourished, and live in conditions where the environment is either degraded or being degraded (2-4). As a result, improving the livelihoods of smallholders through higher and more stable crop yields, while minimizing negative environmental impacts, is essential for achieving global food security and poverty reduction $(3,5)$. Ecosystem services enhanced through biodiversity (such as nutrient cycling, biotic pollination, or pest control) can replace, complement, or interact synergistically with external inputs (such as fertilizers, introduction of pollinator colonies, and pesticides) and should create mutually beneficial environmental and foodsupply scenarios $(6,7)$. Despite advocacy for such "ecological" intensification (6-8), its effectiveness in small versus large holdings is largely unknown. Moreover, smallholding crop systems in developing countries have been largely neglected in ecosystem-services research $(2,4)$.

Yield gaps, defined here as the difference in crop yield between high- and low-yielding farms of a given crop system (Fig. 1), are pervasive for small holdings in many developing countries (7-9). This definition of yield gaps is particularly relevant for smallholders, as the attainable yields in field trials and research centers usually result from applying different technologies (e.g., nutrients provided as manure in crop-livestock smallholding systems versus synthetic fertilizers used in large monocultures in research centers) $(3,7)$. Such empirical estimates of attainable yields are more conservative than modeled potential yields (10), but they are likely achievable with current technology (9). Indeed, the marginal returns from additional inputs can make modeled potential yields nonprofitable for farmers (9). Yield gaps can be partially closed through the provision of optimal amounts and quality of resources, such as water, nutrients, and pollen $(9,11)$. Although fruit or seed set of many crops relies on wild pollinators (12), management for improved pollination services is uncommon in these systems (13), likely contributing to yield gaps globally (11). Indeed, pollination has been neglected even in studies analyzing the continental or global drivers of yield gaps $(5,7,9,10)$. Pollinator deficits may be more relevant than before, as (i) other resources (e.g., nutrients) are increasingly provided (e.g., fertilizers) to crops $(6,8)$; (ii) cultivated area of pollinator-dependent crops is expanding more rapidly than the area of pollinator-independent crops (11); (iii) cultivated area of pollinator-dependent crops is also expanding more rapidly than the stock of managed honey bee colonies (14); and (iv) populations of wild pollinators are increasingly threatened $(15,16)$. Furthermore, pollinator-dependent crops provide essential micronutrients to humans in those regions of the world where micronutrient deficiencies are common (4). To date, it is uncertain to what degree local populations of pollinators need to be enhanced ("flower-visitor density gap"), and how much of the yield gaps $\left(\mathrm{kg} \mathrm{ha}^{-1}\right)$ can be closed by such management (Fig. 1).

Instituto de Investigaciones en Recursos Naturales, Agroecología y Desarrollo Rural (IRNAD), Sede Andina, Universidad Nacional de Río Negro (UNRN) and Consejo Nacional de Investigaciones Científicas y Técnicas (CONICET), Mitre 630, CP 8400, San Carlos de Bariloche, Río Negro, Argentina. ²Departamento de Ecologia, Universidade de Brasília, Campus Universitário Darcy Ribeiro, Brasilia - DF, 70910-900, Brazil; Centre for Ecology, Evolution and Environmental Changes (CE3C). Faculdade de Ciências da Universidade de Lisboa 1749-016 Lisboa, Portugal \& Naturalis Biodiversity Center, postbus 9517, 2300, RA, Leiden, Netherlands. ${ }^{3}$ nstitut national de la recherche agronomique, UR406 Abeilles et Environnement, 228 route de l'Aérodrome, CS40509, F84914, Avignon Cedex 9, France. ${ }^{4}$ Food and Agriculture Organization of the United Nations, Viale delle Terme di Caracalla 00153, Rome, Italy. ${ }^{5}$ Departamento de Zoologia, Universidade Federal da Bahia, Instituto de Biologia, Rua Barão de Geremoabo, S/N, Campus de Ondina, CEP 40170110 Salvador, BA, Brazil. ${ }^{6}$ Departamento de Zootecnia-Centro de Ciências Agrárias, Universidade Federal do Ceará, Campus Universitário do Pici, CEP 60021970, Fortaleza, CE, Brazil. ${ }^{7}$ IPBES Secretariat, Intergovernmental Platform on Biodiversity and Ecosystem Services (IPBES), UN Campus, Platz der Vereinten Nationen 1, D-53113, Bonn, Germany. ${ }^{8}$ Laboratorio Ecotono, Universidad Nacional del Comahue-CONICET, Instituto de Investigaciones en Biodiversidad y Medioambiente, Quintral 1250 , CP 8400, San Carlos de Bariloche, Río Negro, Argentina. ${ }^{9}$ Norwegian Institute for Nature Research, Post Office Box 5685 Sluppen, N0-7485, Trondheim, Norway. ${ }^{10}$ Key Laboratory for Insect-Pollinator Biology of the Ministry of Agriculture, Institute of Apicultural Research, Chinese Academy of Agricultural Sciences, 100093, Beijing, China. ${ }^{11}$ Pontifícia Universidade Católica do Rio Grande do Sul (PUCRS), Av. Ipiranga, 6681, CEP 90619900 Porto Alegre, RS, Brazil. ${ }^{12}$ Department of Plant Protection, Faculty of Agriculture, Bogor Agricultural University. Jln. Kamper, Darmaga, Bogor 16680, West Java, Indonesia. ${ }^{13}$ Laboratorio investigaciones en Abejas (LABUN), Departamento de Biología, Universidad Nacional de Colombia, Sede Bogotá, CP11001, Bogotá, Colombia. ${ }^{14}$ Departamento de Educação em Ciências Agrárias e da Terra, Universidade Federal de Sergipe, Campus do Sertão, Rodovia Engenheiro Jorge Neto. Silos KM 0, CEP 49680000 , Nossa Senhora da Gloria, SE, Brazil. ${ }^{15}$ Institute of Agriculture and Animal Science, Rampur, Chitwan, Nepal. ${ }^{16}$ Embrapa Semiárido, BR 428, Km 152, C.P. 23, zona rural, CEP 56302970, Petrolina, PE, Brazil. ${ }^{17} \mathrm{Jardim}$ Botânico do Rio de Janeiro (JBRJ), Rua Pacheco Leão 915, CEP 22460030, Rio de Janeiro, RJ, Brazil. ${ }^{18}$ Laboratório de Ciências Ambientais, Universidade Estadual do Norte Fluminense Darcy Ribeiro, CEP 28013620, Campos dos Goytacazes, RJ, Brazil. ${ }^{19}$ University of Zimbabwe, Faculty of Agriculture, Crop Science Department, Post Office Box MP167, Mt Pleasant, Harare, Zimbabwe.

${ }^{20}$ Conservation and Management of Pollinators for Sustainable Agriculture through Ecosystem Approach project, Honey Bee Research Institute, National Agricultural Research Centre, Park Road, Post Office Box 44000, Islamabad, Pakistan. ${ }^{21}$ Kenya Agricultural and Livestock Research Organisation-Sericulture, Post Office Box 7816 code 01000 Thika, Kenya. ${ }^{22}$ College of Agriculture and Natural Sciences, School of Biological Sciences, University of Cape Coast, Cape Coast, Ghana. ${ }^{23}$ Embrapa Recursos Genéticos e Biotecnologia, Parque Estação Biológica, W5 Norte (final), CEP 70770917, Brasilia, DF, Brazil. ${ }^{24}$ Instituto do Meio Ambiente e Recursos Hídricos (INEMA)-UR Extremo Sul, Rua Viena, no. 425, Bairro Dinnah Borges, CEP 45820970, Eunápolis, BA, Brazil. ${ }^{25}$ G.B. Pant Institute of Himalayan Environment and Development, Kosi-Katarmal, Almora-263 643 Uttarakhand. India. ${ }^{26}$ Department of Plant Pest Diseases, Faculty of Agriculture, University of Brawijaya. Jl. Veteran, Malang 65145 East Java, Indonesia. ${ }^{27}$ Universidade de São Paulo, Escola Politécnica, Av. Prof. Luciano Gualberto Travessa 3, n.158, CEP 05508010, São Paulo, SP, Brazil. ${ }^{28}$ South African National Biodiversity Institute, Kirstenbosch Research Centre, Private Bag X7, Claremont, 7735, South Africa. ${ }^{29}$ Conservation Ecology and Entomology, Stellenbosch University, Private Bag X1, 7602. Matieland, South Africa. ${ }^{30}$ Centro de Pesquisa Emílio Schenk, Fundação Estadual de Pesquisa Agropecuária (Fepagro Vale do Taquari), $1^{\circ}$ Distrito, Fonte Grande, Caixa Postal 12, CEP 95860000, Taquari, RS, Brazil.

*Corresponding author. E-mail: Igaribaldi@unrn.edu.ar 
We recorded flower-visitor density, flower-visitor richness, and crop yield in 344 fields of 33 crop systems across small and large holdings in Africa, Asia, and Latin America (figs. S1 and S2). To avoid the limitations of different methodologies, and considering the global nature of our focus, we performed coordinated experiments (17) over a 5-year period (2010-2014)-a collaborative approach that encompassed large geographic ranges involving a standardized protocol. This sampling protocol (18) used fields with contrasting flower-visitor density and richness not confounded with management variables other than the ones that were employed to influence flower-visitor assemblages (table S1). Therefore, crop systems are defined as a crop species in a particular year and region subject to similar management, except for flower-visitor density and richness (table S1). Following this protocol (18), flower-visitor density was measured by scan sampling a fixed number of open floral units (hereafter "flowers") in each of four subplots in each field, on at least four dates during the main flowering period (19). Flower-visitor spe-
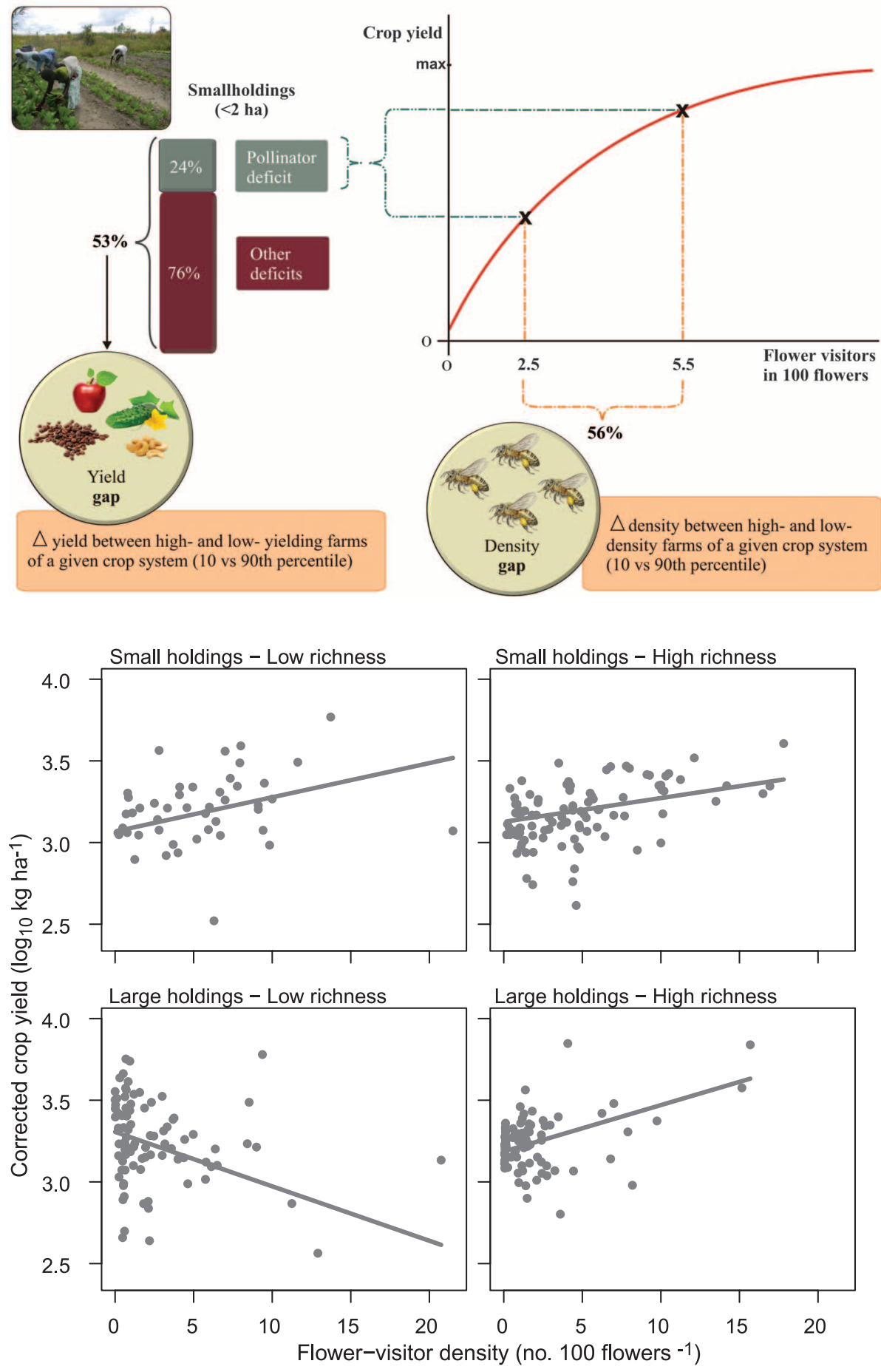

cies richness was measured by netting all visitors of crop flowers along six 25-m-long and 2-m-wide transects for herbaceous crops (or six pairs of adjacent trees for orchard crops). Crop yield was measured by harvesting all the fruits or seeds of 5 to 10 entire plants $\left(\mathrm{kg} \mathrm{plant}^{-1}\right)$ and then multiplying those values by plant density (plants ha ${ }^{-1}$ ), or by harvesting 1 to $5 \mathrm{~m}^{2}$, according to the crop (18). Crop yield $\left(\log _{10} \mathrm{~kg} \mathrm{ha}^{-1}\right)$ was analyzed through (hierarchical) mixed-effects models with fields nested within crop systems. Fixed effects were flower-visitor density (number of visitors in

Fig. 1. Pollinator deficit is defined here as the amount of yield gap that can be accounted by closing flower-visitor density gap. Worldwide, for $<2$-ha fields, our study shows that yield gaps could be closed by a median of $24 \%$ (mean $=31 \%$ ) through higher flower-visitor density (table S2). For larger fields, such a level of yield benefits only occurred if they sustained high flower-visitor richness (Fig. 2). Although the relation between crop yield and flowervisitor density is expected to be positive but asymptotic (11), our study supports a linear relation, demonstrating that the highest levels of flowervisitor density observed around the world are still at nonsaturating values.

Fig. 2. Worldwide, the benefits of flower-visitor density to crop yield are greater for smaller than larger holdings, and when flower-visitor richness is higher. Moreover, high richness can compensate this negative influence of field size. Each point is a field within a crop system; lines are the fixed-effect predictions from the best hierarchical model without covariables. Small ( $<2 \mathrm{ha}$ ) versus large holdings, and low ( $<3$ species) versus high richness, are categories only for graphical purposes, while the model considers field size and species richness as quantitative variables. By using the same protocol, we could express density as number of visitors in 100 crop flowers, avoiding standardizations to integrate results from different crop systems. Because yield $\left(\mathrm{kg} \mathrm{ha}^{-1}\right)$ is harvested in different magnitudes for different crop species (e.g., coffee versus tomatoes), we present the crop yield after subtracting the random intercept for each crop system. 


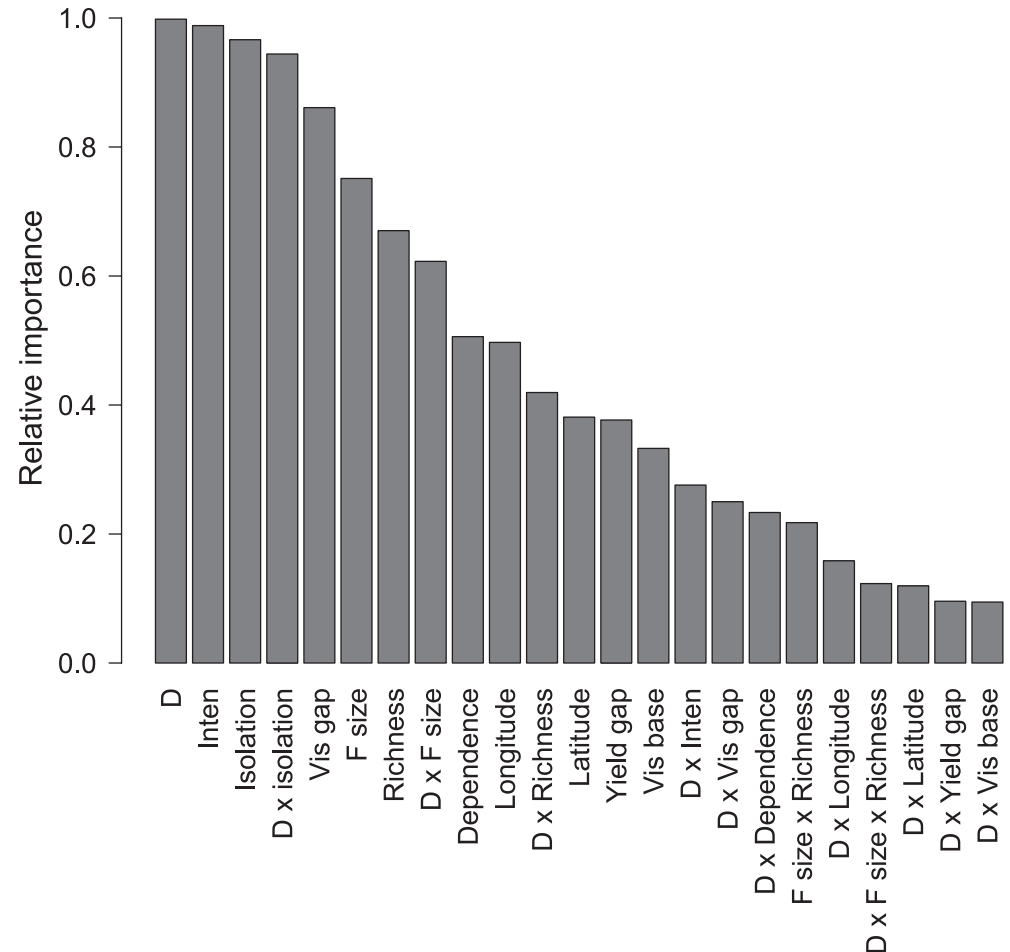

Fig. 3. Flower-visitor density (D) was the most important predictor of crop yield for pollinatordependent crops globally. The relative importance is the sum of the Akaike information criterion weights of the models with each predictor. Inten, level of conventional intensification; Isolation, distance to seminatural or natural areas; Vis gap, magnitude of flower-visitor gap; F size, field size; Richness, flower-visitor richness; Dependence, crop pollinator dependence; Vis base, baseline level of flower-visitor density.

100 crop flowers), flower-visitor richness (number of species per field in 30 min of net sampling), field size $\left(\log _{10}\right.$ ha), and their interactions (19). Random effects were intercepts and slopes for each crop system for the relation between crop yield and flower-visitor density and richness. Although our focus was on developing countries, research partners from Norway followed the same protocol in three crop systems, and their data were included in the analyses for comprehensiveness.

Globally, yield gaps were large and common across fields in each crop system (Fig. 1 and table S2). Crop yield in low-yielding fields (10th percentile) was, on average, only $47 \%$ of the value in highyielding fields (90th percentile; see table S2 for $\mathrm{kg} \mathrm{ha}^{-1}$ ). Differences in flower-visitor density (i.e., flower-visitor density gaps) were similarly large (Fig. 1 and table S2). The fields with low flowervisitor density (10th percentile: 2.5 flower visitors in 100 flowers on average across crop systems) had only $44 \%$ of the individuals of the fields with high values (90th percentile: 5.5 flower visitors in 100 flowers on average across crop systems). These results indicate that even for crops of a given variety planted within a particular region and year, and managed similarly, there are large opportunities to increase flower-visitor densities and yields to the values of the best farms (90th percentile).

The effects of flower-visitor density on crop yield were largely influenced by field size (which ranged from 0.1 to 327.2 ha in our study) and flower-visitor richness (which ranged from 0 to 11 species in our study), as reflected by a three- way interaction (Fig. 2 and table S3). For smallholdings worldwide, crop yield increased linearly with flower-visitor density, suggesting that inadequate pollination quantity and/or quality is partly responsible for yield gaps $(11,20)$. These benefits were irrespective of flower-visitor richness. In contrast, for larger holdings, the benefits of flower-visitor density on crop yield were greater in fields with higher flower-visitor richness (Fig. 2 and table S3). Therefore, greater flower-visitor richness could compensate the negative influence that field size had on the relationship (slope) between crop yield and flower-visitor density. For example, in fields with only one flower-visitor species, the increase in crop yield per unit of flower-visitor density was $106 \%$ higher for fields of 2 ha than for those of 20 ha. However, this difference was reduced to only $16 \%$ when four flower-visitor species were present. Globally, our results suggest that the effectiveness of ecological intensification (represented here by flower-visitor density) differs between small and large holdings, being greater for small holdings and when species richness is enhanced.

To test if these results could be explained by environmental and management aspects that covary with flower-visitor density, flower-visitor richness, or field size (table $\mathrm{S} 1$ ), we added to the previous mixed-effects model the following fixed effects: level of conventional intensification (a quantitative index based on the presence of monocultures, synthetic fertilizers, herbicides, pesticides, and fungicides) (19); isolation from seminatural or natural habitats $\left(\log _{10} \mathrm{~km}\right)$; crop pollinator dependence (\%); latitude (decimal degrees); longitude (decimal degrees); baseline level of flower-visitor density (10th percentile: number per 100 flowers); magnitude of yield gap (\%); magnitude of flower-visitor gap (\%); and the two-way interactions between each of these covariables and flower-visitor density (19). The best-fitting model (i.e., lower corrected Akaike's information criterion, $\mathrm{AICc}$ (19) was then derived from evaluation of all possible combinations of predictors and covariables, including a model without predictors. The influences of flower-visitor density, flowervisitor richness, field size, and their interactions were still included as predictors of crop yield in the best model, in addition to the intensification level, isolation from natural habitats, and flowervisitor gap (table S3). Importantly, fixed-effect values (and standard errors) for these predictors were of similar magnitude in the models with and without covariables (table S3), reflecting their independent contribution from the covariables in predicting crop yield [see also VIF (variance inflation factor) values in table S3]. The sum of the AICc weights of all the models for each predictor and covariable was used as an estimate of its relative importance (19). Notably, among all the variables we tested, flower-visitor density was the most important predictor of crop yield (Fig. 3). As expected (21), the level of conventional intensification was an important predictor of crop yield (Fig. 3), showing a positive relation (table S3). Crop yield decreased with isolation from natural habitats, and more so when flower-visitor density was lower (table S3). Worldwide, our data show that effects of flower-visitor density, flower-visitor richness, and field size are highly relevant in the context of, and not confounded by, other environmental and management variables affecting crop yield.

Our best-fitting model (table S3) allows the estimation of the degree to which yield gaps $\left(\mathrm{kg} \mathrm{ha}^{-1}\right)$ can be closed by enhancing local populations of flower visitors for a given field size and several other key management and environmental covariables (note the high coefficient of determination, $R^{2}$, of 0.97 in table S3). In fields of less than 2 ha, the enhancement of flower-visitor density in fields with the lowest values (10th percentile) to those of the best fields (90th percentile) should close yield gaps by a median of $24 \%$ (Fig. 1 and table S2). The remaining $76 \%$ of the yield gap may be partially closed by technologies oriented to the optimal provision and efficient use of other resources (e.g., radiation, nutrients, water), including sowing date, plant density, genetic material, conservation agriculture, and integrated pest management, among many others $(5-7,9,10)$. In contrast, for larger fields, such level of yield benefits from enhancement of flowervisitor density occurs only if these fields have high flower-visitor richness (Fig. 2 and table S2). In our study, the influences of field size were not confounded by several important environmental and management variables affecting crop yield (table S3). Lower benefits from flower-visitor density in larger fields may reflect the fact that they are only 
pollinated by flower visitors with large foraging ranges, which are usually generalist species, such as honey bees (12). In accordance with this hypothesis, we found greater dominance of Apis spp. in larger holdings regardless of species richness (fig. S3), and that flower-visitor density effects were enhanced when richness increased in large fields (Fig. 2). Such synergistic influences among pollinator species on crop yield $\left(\mathrm{kg} \mathrm{ha}^{-1}\right)$ are likely due to different nonexclusive mechanisms (22), including pollination niche complementarity $(23,24)$, interspecific interactions $(25,26)$, or raising the chances of providing effective pollinator species (i.e., sampling effects of biodiversity) $(27,28)$.

Pollinator deficits have been neglected from previous global or continental yield gap analyses $(5,7,9,10)$. However, here we found that they are responsible to a large degree for yield gaps of pollinator-dependent crops in small holdings (Fig. 1 and table S2), even after considering several environmental and management predictors of crop yield (Fig. 3). Indeed, flower-visitor density was the most important predictor of crop yield. Closing flower-visitor density gaps is a realistic objective, as our figures are based on the densities observed in real-world farms (i.e., the difference between the 90th and 10th percentiles). Unfortunately, recent studies suggest that flower-visitor assemblages in agroecosystems are increasingly threatened because of declining floral abundance and diversity, as well as increasing exposure to pesticides and parasites $(15,16)$. Such trends can be reversed by a combination of practices, the effectiveness of which is context dependent, including sowing flower strips and planting hedgerows, providing nesting resources, more targeted use of pesticides, and/or restoration of seminatural and natural areas adjacent to crops (table S1) $(13,29)$.

Enhancing smallholder livelihoods through greater crop yields while reducing negative environmental impacts from agriculture is one of the greatest challenges for humanity $(3,5)$. Moreover, from a food-security point of view, pollinatordependent crops provide essential micronutrients to human health where needed (4). Our data indicate that the effectiveness of ecological intensification through pollination services was greater for small, rather than large, holdings. Using pollination services as a case study, we demonstrated that ecological intensification can create mutually beneficial scenarios between biodiversity and crop yields worldwide.

\footnotetext{
REFERENCES AND NOTES

1. S. K. Lowder, J. Skoet, S. Singh, "What do we really know about the number and distribution of farms and family farms worldwide?" Background paper for the State of Food and Agriculture 2014 (Food and Agriculture Organization of the United Nations, Rome, 2014).

2. P. R. Steward et al., Agric. Food Security 3, 5 (2014).

3. M. Herrero et al., Science 327, 822-825 (2010)

4. R. Chaplin-Kramer et al., Proc. R. Soc. B Biol. Sci. 281 20141799 (2014).

5. H. C. J. Godfray et al., Science 327, 812-818 (2010).

6. R. Bommarco, D. Kleijn, S. G. Potts, Trends Ecol. Evol. 28, 230-238 (2013).

7. P. Tittonell, K. E. Giller, Field Crops Res. 143, 76-90 (2013).

8. J. A. Foley et al., Nature 478, 337-342 (2011).

9. N. D. Mueller et al., Nature 490, 254-257 (2012).
}

10. D. B. Lobell, K. G. Cassman, C. B. Field, Annu. Rev. Environ. Resour. 34, 179-204 (2009).

11. L. A. Garibaldi, M. A. Aizen, A. M. Klein, S. A. Cunningham, L. D. Harder, Proc. NatI. Acad. Sci. U.S.A. 108, 5909-5914 (2011)

12. L. A. Garibaldi et al., Science 339, 1608-1611 (2013).

13. L. A. Garibaldi et al., Front. Ecol. Environ. 12, 439-447 (2014)

14. M. A. Aizen, L. D. Harder, Curr. Biol. 19, 915-918 (2009).

15. D. Goulson, E. Nicholls, C. Botías, E. L. Rotheray, Science 347 1255957 (2015).

16. M. Rundlöf et al., Nature 521, 77-80 (2015).

17. L. H. Fraser et al., Front. Ecol. Environ. 11, 147-155 (2013)

18. B. E. Vaissière, B. M. Freitas, B. Gemmill-Herren, Protocol to detect and assess pollination deficits in crops: a handbook for its use (Food and Agriculture Organization of the United Nations, Rome, 2011)

19. See supplementary materials on Science Online.

20. M. A. Aizen, L. D. Harder, Ecology 88, 271-281 (2007)

21. V. Seufert, N. Ramankutty, J. A. Foley, Nature 485, 229-232 (2012)

22. T. Tscharntke, A. M. Klein, A. Kruess, I. Steffan-Dewenter, C. Thies, Ecol. Lett. 8, 857-874 (2005)

23. P. Hoehn, T. Tscharntke, J. M. Tylianakis, I. Steffan-Dewenter Proc. R. Soc. B Biol. Sci. 275, 2283-2291 (2008)

24. J. Fründ, C. F. Dormann, A. Holzschuh, T. Tscharntke, Ecology 94, 2042-2054 (2013)

25. L. G. Carvalheiro et al., Ecol. Lett. 14, 251-259 (2011)

26. C. Brittain, N. Williams, C. Kremen, A. M. Klein, Proc. Biol. Sci. 280, 20122767 (2013)

27. B. J. Cardinale et al., Nature 443, 989-992 (2006)

28. M. Schleuning, J. Fründ, D. García, Ecography 38, 380-392 (2015)

29. D. Kleijn et al., Nat. Commun. 6, 7414 (2015).

\section{ACKNOWLEDGMENTS}

Funding was provided by the Global Environment Fund, United Nations Environment Program, United Nations Food and Agriculture Organization (GEF/UNEP/FAO) Global Pollination Project, with additional support to the Food and Agriculture Organization of the United Nations from the Norwegian Environment Agency for a project on "Building Capacity in the Science-Policy Interface of Pollination Services," and from the International Fund for Agricultural Development for the development of the sampling protocol (18). Other funding: Conselho Nacional de Desenvolvimento Científico e Tecnológico Brazil, CONICET Argentina (PIP 114-201101-00201). Norwegian Environment Agency (2012/16642), The Research Council of Norway (225019), and Universidad Nacional de Río Negro Argentina (PI 40-B-259. PI 40-B-399). The data used in the analyses are available in the supplementary materials. L.A.G., L.G.C., and J.H. compiled data; L.A.G. and L.G.C. analyzed data; L.A.G. wrote the first version of the manuscript; the authors named between L.A.G. and J.Ås. discussed and revised earlier versions of the manuscript. The authors named between J.An and H.Z. are listed alphabetically, as they contributed equally, gathering field data, providing corrections to subsequent manuscript drafts, and discussing ideas. G. Andersson, B. Geslin, and P. Steward provided insightful comments on previous versions of this paper.

\section{SUPPLEMENTARY MATERIALS}

www.sciencemag.org/content/351/6271/388/suppl/DC1 Materials and Methods

Figs. S1 to S3

Tables S1 to S3

References (30-44)

Database S1

22 June 2015; accepted 15 December 2015

10.1126/science.aac7287

\section{Biogenesis and function of tRNA fragments during sperm maturation and fertilization in mammals}

Upasna Sharma, ${ }^{1 *}$ Colin C. Conine, ${ }^{1 *}$ Jeremy M. Shea, ${ }^{1}$ Ana Boskovic, ${ }^{1}$ Alan G. Derr, ${ }^{2,3}$ Xin Y. Bing, ${ }^{1}$ Clemence Belleannee, ${ }^{4}$ Alper Kucukural, ${ }^{2,3}$ Ryan W. Serra, ${ }^{1}$ Fengyun Sun, Lina Song, ${ }^{1}$ Benjamin R. Carone, ${ }^{1}$ Emiliano P. Ricci, ${ }^{5} \dagger$ Xin Z. Li, ${ }^{1,5} \ddagger$ Lucas Fauquier, ${ }^{1}$ Melissa J. Moore ${ }^{1,5,6}$ Robert Sullivan, ${ }^{4}$ Craig C. Mello, ${ }^{2,5,6}$ Manuel Garber, ${ }^{2,3}$ Oliver J. Rando ${ }^{1} \S$

Several recent studies link parental environments to phenotypes in subsequent generations. In this work, we investigate the mechanism by which paternal diet affects offspring metabolism. Protein restriction in mice affects small RNA (sRNA) levels in mature sperm, with decreased let-7 levels and increased amounts of $5^{\prime}$ fragments of glycine transfer RNAs (tRNAs). In testicular sperm, tRNA fragments are scarce but increase in abundance as sperm mature in the epididymis. Epididymosomes (vesicles that fuse with sperm during epididymal transit) carry RNA payloads matching those of mature sperm and can deliver RNAs to immature sperm in vitro. Functionally, tRNA-glycine-GCC fragments repress genes associated with the endogenous retroelement MERVL, in both embryonic stem cells and embryos. Our results shed light on sRNA biogenesis and its dietary regulation during posttesticular sperm maturation, and they also link tRNA fragments to regulation of endogenous retroelements active in the preimplantation embryo.

A ccumulating evidence indicates that parental environments can affect the health of offspring. For example, paternal nutrition influences offspring metabolism in mammals (1). Our prior published work showed that male mice consuming a low-protein diet fathered offspring exhibiting altered hepatic cholesterol biosynthesis, relative to the offspring of control males (2). The mechanisms by which paternal conditions reprogram offspring phenotype remain elusive, as males can influence offspring via the sperm epigenome, microbiome 


\section{Science}

\section{Mutually beneficial pollinator diversity and crop yield outcomes in small and large farms}

Lucas A. Garibaldi, Luísa G. Carvalheiro, Bernard E. Vaissière, Barbara Gemmill-Herren, Juliana Hipólito, Breno M. Freitas, Hien T. Ngo, Nadine Azzu, Agustín Sáez, Jens Åström, Jiandong An, Betina Blochtein, Damayanti Buchori, Fermín J. Chamorro García, Fabiana Oliveira da Silva, Kedar Devkota, Márcia de Fátima Ribeiro, Leandro Freitas, Maria C. Gaglianone, Maria Goss, Mohammad Irshad, Muo Kasina, Alípio J.S. Pacheco Filho, Lucia H. Piedade Kiill, Peter Kwapong, Guiomar Nates Parra, Carmen Pires, Viviane Pires, Ranbeer S. Rawal, Akhmad Rizali, Antonio M. Saraiva, Ruan Veldtman, Blandina F. Viana, Sidia Witter and Hong Zhang

Science 351 (6271), 388-391.

DOI: $10.1126 /$ science.aac7287

\section{More-diverse pollinators improve crop yields}

It is known that increased pollinator diversity can improve the yield of agricultural crops. However, how best to both produce food and maintain diversity is still debated. Garibaldi et al. show that on small farms, which provide food for the most vulnerable populations globally, pollinator diversity can significantly increase productivity. Thus, the management of crops and surrounding areas for ecological health is likely to benefit both wild pollinator populations and farmers.

Science, this issue p. 388

ARTICLE TOOLS

SUPPLEMENTARY MATERIALS

REFERENCES

PERMISSIONS http://science.sciencemag.org/content/351/6271/388

http://science.sciencemag.org/content/suppl/2016/01/20/351.6271.388.DC1

This article cites 29 articles, 5 of which you can access for free http://science.sciencemag.org/content/351/6271/388\#BIBL

http://www.sciencemag.org/help/reprints-and-permissions

Use of this article is subject to the Terms of Service

Science (print ISSN 0036-8075; online ISSN 1095-9203) is published by the American Association for the Advancement of Science, 1200 New York Avenue NW, Washington, DC 20005. 2017 (C) The Authors, some rights reserved; exclusive licensee American Association for the Advancement of Science. No claim to original U.S. Government Works. The title Science is a registered trademark of AAAS. 